Murali Dharan Bashyam · Leena Bashyam

Gorinabele R. Savithri · Munimanda Gopikrishna

Vartul Sangal · Akela Radha Rama Devi

\title{
Molecular genetic analyses of $\beta$-thalassemia in South India reveals rare mutations in the $\beta$-globin gene
}

Received: 26 January 2004 / Accepted: 6 May 2004 / Published online: 24 July 2004

(C) The Japan Society of Human Genetics and Springer-Verlag 2004

\begin{abstract}
$\beta$-thalassemia is the most prevalent single-gene disorder. Since no viable forms of treatment are available, the best course is prevention through prenatal diagnosis. In the present study, the prevalence of $\beta$-thalassemia was extensively investigated in the South Indian population, especially from the state of Andhra Pradesh. Screening for causal mutations was carried out on genomic DNA isolated from patient blood samples by using the routine reverse dot blot (RDB) and amplification refractory mutation system-polymerase chain reaction (ARMSPCR) techniques. DNA sequencing wa0s performed wherever necessary. Among the nine mutations identified, four, including IVS-1-5 (G-C) (IVS1 + 5G $>\mathrm{T})$, codon 41/ 42 (-TTCT) (c.124_127delTTCT), codon 15 (G-A)
\end{abstract}

M. D. Bashyam · M. Gopikrishna · V. Sangal

National Genomics and Transcriptomics Facility,

Centre for DNA Fingerprinting and Diagnostics (CDFD),

Nacharam, Hyderabad, 500076, India

M. D. Bashyam

Laboratory of Molecular Oncology,

Centre for DNA Fingerprinting and Diagnostics (CDFD),

Nacharam, Hyderabad, 500076, India

Present address: M. D. Bashyam

Department of Pathology, CCSR 3240, 269 Campus Drive, Stanford University School of Medicine, Stanford, CA, 94305-5176, USA

L. Bashyam · A. R. R. Devi $(\bowtie)$

Diagnostics division, Centre for DNA Fingerprinting and

Diagnostics (CDFD), Nacharam,

Hyderabad, 500076, India

E-mail: radha@cdfd.org.in

Tel.: +91-40-27171462

Fax: +91-40-27155479

Present address: L. Bashyam

LSRA, Microbiology and Immunology,

Fairchild D327, 299 Campus Drive,

Stanford University School of Medicine,

Stanford, CA, 94305-5124, USA

G. R. Savithri

Laboratory of Molecular and Cellular Biology,

Centre for DNA Fingerprinting and Diagnostics (CDFD),

Nacharam, Hyderabad, 500076, India (c. $47 \mathrm{G}>\mathrm{A}$ ), and $\mathrm{HbS}$ (sickle mutation) (c.20A $>\mathrm{T}$ ) mutations, accounted for about $98 \%$ of the total positive cases. Two mutations viz. codon 8/9 (+G) (c.27_28insG) and $\mathrm{HbE}$ (codon $26 \mathrm{G}-\mathrm{A})(\mathrm{c} .79 \mathrm{G}>\mathrm{A}$ ) exhibited a very low frequency of occurrence, whereas the IVS-1-1 (G-T) $(\mathrm{IVS} 1+1 \mathrm{G}>\mathrm{T})$ and the 619 bp deletion (c.366_494del) mutations were absent. We also identified certain rare mutations during the diagnostic evaluation. Gene sequencing confirmed the codon $30(\mathrm{G}-\mathrm{C})(\mathrm{c} .92 \mathrm{G}>\mathrm{C})$ mutation and the rare codon 5 (-CT) (c.17_18delCT) and IVS-II-837 (T-G) (IVSII-14T > G) mutations. This is the first report of the IVS II 837 mutation in the Indian population. We also report a novel diagnostic application during RDB-based screening for the detection of the (c. $92 \mathrm{G}>\mathrm{C}$ ) mutations. Such a comprehensive mutation screening is essential for prenatal diagnosis of $\beta$-thalassemia and control of this highly prevalent monogenic disorder in the Indian population.

Keywords Thalassemia $\beta$-globin $\cdot$ India $\cdot$

Mutation $\cdot$ Prenatal diagnosis

\section{Introduction}

Hereditary hemoglobinopathies constitute a group of heterogeneous autosomal recessive disorders. $\beta$-thalassemia, the most common autosomal recessive single-gene disorder of hemoglobin synthesis is characterized by hypochromic micro cyclic hemolytic anemia. The disease runs a chronic course requiring repeated blood transfusions that usually leads to iron overload, and no other effective therapy is presently available. Left untreated, affected individuals manifest failure to thrive and shortened life expectancy. Extensive research in identifying the molecular basis of the disease has led to the identification of more than 200 mutations in the $\beta$-globin gene located at $11 \mathrm{p} 15.5$. The mutations result in transcriptional failure of $\beta$-globin synthesis with a corresponding decrease in the amount of functionally active protein. 
$\beta$-thalassemia is the commonest single-gene disorder in the Indian population (Verma 1994), with $10 \%$ of the total world thalassemics born in India every year. With this enormous burden and no effective treatment available, prenatal diagnosis and carrier status detection are the most appropriate preventive measures to contain the disease and reduce the load of the mutant alleles in the gene pool (Agarwal et al. 2003). Out of over 200 causal $\beta$-globin gene mutations, 11 have been shown to be common in India. Among these 11, six account for about $94 \%$ of all positive cases. These include IVS1 $+1 \mathrm{G}>\mathrm{T}$, IVS1 + 5G $>$ T, c.124_127delTTCT, c. $47 \mathrm{G}>\mathrm{A}$, c.366_494del, and c.20A $>$ T. The other two less common mutations are c. 27 28insT and c. $79 \mathrm{G}>\mathrm{A}$. The spectrum of mutations, however, is different in different population groups within India. There is a paucity of information regarding the frequency of $\beta$-thalassemia mutations in the South Indian population. The present study of 123 probands (105 from South India and the rest from other states) with suspected $\beta$-globin gene defects is the first attempt of its kind from the South Indian population. All affected families were advised about prenatal diagnosis for future pregnancies as a prophylactic measure.

\section{Materials and methods}

\section{Patients and samples}

The total number of samples analyzed in this study was 397 (which includes family members of the probands), including 234 males and 163 females. A total of 123 proband samples were analyzed, and these included 77 cases from Andhra Pradesh (AP) and 46 received from other states during this study. In most cases, the patients themselves reported to the Centre for DNA Fingerprinting and Diagnostics (CDFD) for screening, whereas in some cases, blood samples were received from various hospitals. Ethical consent was obtained from the institute ethical committee to carry out genetic testing on the blood samples as per the standard norms of the Institute in accordance with the Helsinki declaration of 1975. The consent of patients and their family members was obtained before collecting blood samples. Out of the total 76 affected cases from AP, as high as $58 \%$ were consanguineous. These included uncle/niece marriages $(26.5 \%)$, first cousin marriages $(22.5 \%)$, and second cousin marriages $(9 \%)$. The incidence of consanguinity in the Muslim population $(70 \%)$ was markedly higher than in the Hindu population $(47 \%)$.

\section{Reverse dot blot}

Genomic DNA was isolated from the blood samples as previously described (Old 1986; Miller et al. 1988). Briefly, the red blood cells were lysed and the DNA was purified from the white blood cells by ethanol precipitation following phenol and chloroform extractions. Reverse dot blot (RDB) analysis was employed for detecting seven common mutations in the $\beta$-globin gene, including IVS1 $+1 \mathrm{G}>\mathrm{T}$, IVS1 $1+5 \mathrm{G}>\mathrm{T}$, c.27_28insT, c.124_127delTTCT, c.47G $>$ A, c.79G $>A, \quad$ and c. $20 \mathrm{~A}^{-}>\mathrm{T}$, as previously described (Maggio et al. 1993; Cai et al. 1994). Briefly, two oligonucleotides were used for each mutation, one containing the wild type sequence and the other containing the mutated sequence. The oligonucleotide pair for each mutation was blotted side by side on a nylon membrane (the wild type oligonucleotide on the left side and the mutated oligonucleotide on the right side) and PCR-amplified $\beta$-globin gene from genomic DNA of each sample was hybridized on to the membranes. Depending on whether the PCR products hybridized to the wild type or the mutated oligonucleotides for each mutation, the mutation status of each sample was determined. The sequence of each oligonucleotide used for the RDB is given in Table 1. The eighth mutation, the c.366 494del, was evident from the size of the PCR product, so no RDB was necessary. The Biotinylated primer pair (PCO6 and China 1, see Fig. 1) was used to amplify the promoter region, the first and the second exons, and the first intron of the $\beta$-globin gene from DNA isolated from each patient. The sequence of the two-biotinylated primers is China 1tcattcgtctgtttcccatt and PCO6-gtacggetgtcatcacttagacctca. The PCR product was then used for the RDB analyses as previously described (Maggio et al. 1993; Cai et al. 1994). In this way, seven mutations could be tested for each sample in a single blot.

\section{ARMS-PCR, PCR-REA, and DNA sequencing}

The mutations detected in all the cases were confirmed by using the allele-specific amplification refractory mutation system-polymerase chain reaction (ARMS-

Table 1 Oligonucleotides used for reverse dot blot (RDB)

\begin{tabular}{|c|c|c|}
\hline Name & Sequence & Length \\
\hline $\mathrm{IVS} 1+1 \mathrm{G}>\mathrm{T}-\mathrm{NP}^{\mathrm{a}}$ & Ataccaacctgcccag & 16-mer \\
\hline $\mathrm{IVS} 1+1 \mathrm{G}>\mathrm{T}-\mathrm{MP}^{\mathrm{a}}$ & Ctgggcagtttggtat & 16-mer \\
\hline IVS1 $+5 G>T-N P$ & Ccttgataccaacctgc & 17-mer \\
\hline $\mathrm{IVS} 1+5 \mathrm{G}>\mathrm{T}-\mathrm{MP}$ & Gcaggttgctatcaag & 16-mer \\
\hline c. 27 28insT-NP & Aggagaagtctgccgtt & 17-mer \\
\hline c. $27^{-}$28insT-MP & Cggcagaccttctcet & 16-mer \\
\hline c. $47 \overline{\mathrm{G}}>\mathrm{A}-\mathrm{NP}$ & Cctgtggggcaaggtga & 17-mer \\
\hline c. $47 \mathrm{G}>\mathrm{A}-\mathrm{MP}$ & Ccctgtagggcaaggtga & 18-mer \\
\hline c.124_127delTTCT-NP & Cagaggttctttgagtcctt & 20-mer \\
\hline c.124_127delTTCT-MP & Caaaggactcaacctctgg & 19-mer \\
\hline c.79G > A-NP & Cagggectcaccacca & 16-mer \\
\hline c. $79 \mathrm{G}>\mathrm{A}-\mathrm{MP}$ & Ttggtggtaaggecet & 16-mer \\
\hline c. $20 \mathrm{~A}>\mathrm{T}-\mathrm{NP}$ & Tgactcctgaggagaagt & 18-mer \\
\hline c. $20 \mathrm{~A}>\mathrm{T}-\mathrm{MP}$ & Cagacttctccacagga & 17-mer \\
\hline
\end{tabular}

${ }^{a} \mathrm{NP}$ and MP denote normal primer and mutant primer, respectively 


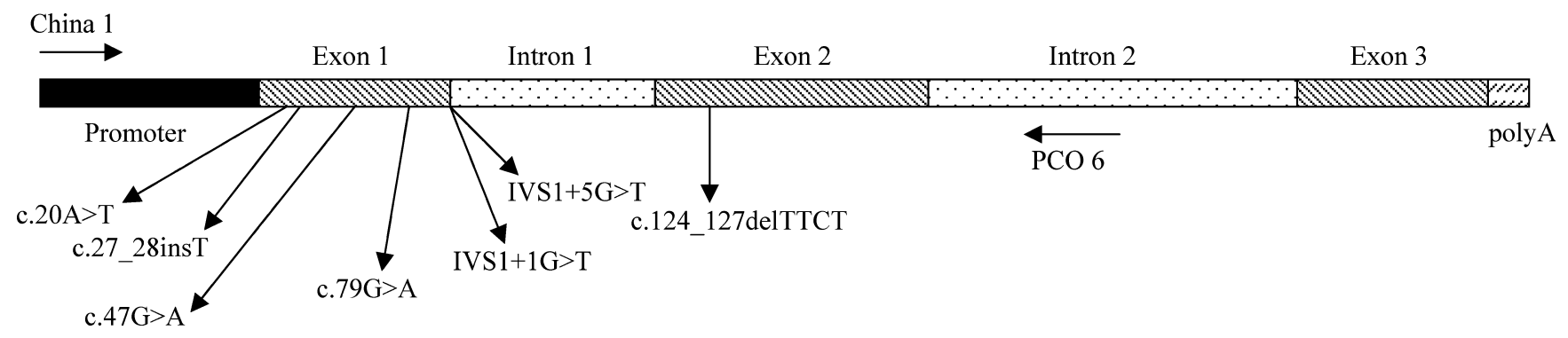

Fig. 1 Location of mutations in the $\beta$-globin gene. The position of major mutations tested in this study are indicated

PCR), as previously described (Newton et al. 1989; Old et al. 1990). Briefly, duplex PCR was carried out for each mutation: one PCR was performed by using primers specific for the mutation and the other PCR was performed as a "control." An 861 bp region located near the $3^{\prime}$ end of the $\beta$-globin gene (that included the c.366_494del mutation region) was amplified in the control PCR. All cases that harbored the c.366_494del mutation, resulted in a product of only $323 \mathrm{bp}^{-}$in the control reaction. Polymerase chain reaction-restriction enzyme analysis (PCR-REA) was carried out to confirm the $\mathrm{HbS}$ mutation as previously described (Gurgey et al. 1993). Briefly, PCR-amplified $\beta$-globin gene sequence was subjected to restriction digestion by the restriction enzyme Dde I. The sickle mutation results in the loss of a Dde I restriction site, and therefore the mutation is easily detected upon resolution of the restricted PCR products on agarose gels. In some cases, the RDB, ARMS-PCR, and PCR-REA did not reveal the presence of the common mutations. In all such cases, automated DNA sequencing was carried out using the ABI PRISM 3100 genetic analyzer and the Beckman Coulter CEQ 8000 genetic analysis system, as per the manufacturer's instructions, in order to identify rare mutations.

\section{Results}

The CDFD is a government nodal centre to which suspected patients are referred for molecular diagnosis of $\beta$ thalassemia. The study was carried out as per norms laid down by the Indian Council of Medical Research, and patient consent was obtained before sample collection. The study includes patients who visited CDFD from 2001 to 2003. One hundred and twenty three proband samples referred to the CDFD from various hospitals in AP and from other Indian states were studied. About three fourths of the total samples from AP were received from the two districts of Hyderabad and Nalgonda (Table 2). Seventy-four percent of the confirmed cases harbored the IVS1 $+5 \mathrm{G}>\mathrm{T}$ mutation (Table 2). The other important mutations detected in this study included the c.47G $>\mathrm{A}$ mutation (seven cases), the c.20A $>$ T mutation (five cases), the c.124_127delTTCT (three cases), c.27_28insT (two cases) and the c.79G $>$ A, and the c.17_18delCT mutations (one case each) (Table 2). However, the IVS1 $+1 \mathrm{G}>\mathrm{T}$ mutation and the c.366_494del mutation were not detected among the samples analyzed from AP, as distinct from studies reported for other parts of the country.

Among the total cases received from other states, the majority of cases harbored the IVS1 $+5 \mathrm{G}>\mathrm{T}$ mutation $(54 \%$, Table 2$)$. The c. $47 \mathrm{G}>$ A mutation was

Table 2 Frequency of common $\beta$-globin mutations in various districts of Andhra Pradesh and in other Indian States. All mutations detected were homozygous, except three compound heterozygous mutations

No. of IVS1+ c.47G $\quad$ c.20A $\quad$ c.124_127 c.27_28 c.79G $>$ A $\quad$ c.17_18 c.92G c.366_494 IVSII- Compound patients $5 \mathrm{G}>\mathrm{T}>\mathrm{A}>\mathrm{T}$ delTTCT insT $^{-}$delCT $>\mathrm{C}$ del $-\mathrm{C}^{\mathrm{T}}>\mathrm{G}$ heterozygotes

AP district

Hyderabad

Nalgonda

Adilabad

East Godavari 7

Krishna

Total

$\begin{array}{rr}39 & 30 \\ 20 & 13 \\ 8 & 7 \\ 7 & 4 \\ 3 & 3 \\ 77 & 57\end{array}$

State

Karnataka 28

West Bengal

Maharashtra

28
11
3
3
1

Gujarat

Sindh

Total

$\begin{array}{rlll}30 & 3 & 2 & 0 \\ 13 & 2 & 2 & 3 \\ 7 & 1 & 0 & 0 \\ 4 & 1 & 1 & 0 \\ 3 & 0 & 0 & 0 \\ 57 & 7 & 5 & 3 \\ & & & \\ 18 & 5 & 0 & 0 \\ 5 & 1 & 1 & 0 \\ 1 & 2 & 0 & 0 \\ 1 & 0 & 0 & 0 \\ 0 & 0 & 0 & 0 \\ 25 & 8 & 1 & 0\end{array}$

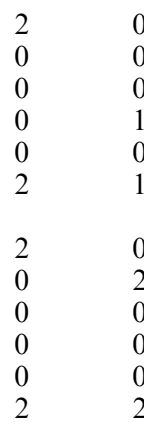

1
0
0
0
0
1
0
0
0
0
0
0

1
0
0
0
0
0
2
0
0
0
0
2

$\begin{array}{lll}0 & 0 & 0 \\ 0 & 0 & 0 \\ 0 & 0 & 0 \\ 0 & 0 & 0 \\ 0 & 0 & 0 \\ 0 & 0 & 0 \\ 0 & 1 & 0 \\ 0 & & 2^{\mathrm{a}} \\ 0 & & 0 \\ 2 & & 0 \\ 0 & & 1^{\mathrm{b}} \\ 2 & 1 & 3\end{array}$

${ }^{\text {a }}$ Both cases were c.79G $>$ A and IVS $1+5 \mathrm{G}>\mathrm{T}$ compound heterozygotes

${ }^{\mathrm{b}}$ This case was a c.366_494del and IVS1 $+5 \mathrm{G}>\mathrm{T}$ compound heterozygote 
a
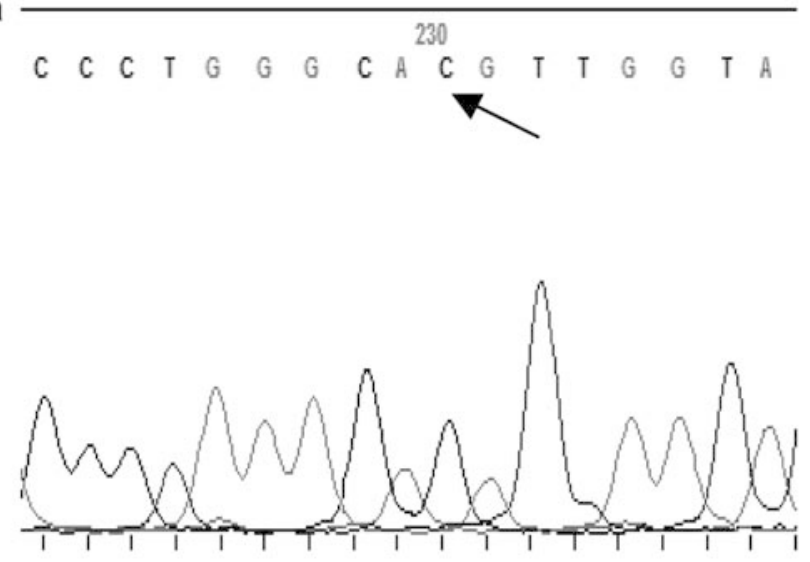

c. $92 \mathrm{G}>\mathrm{C}$ b
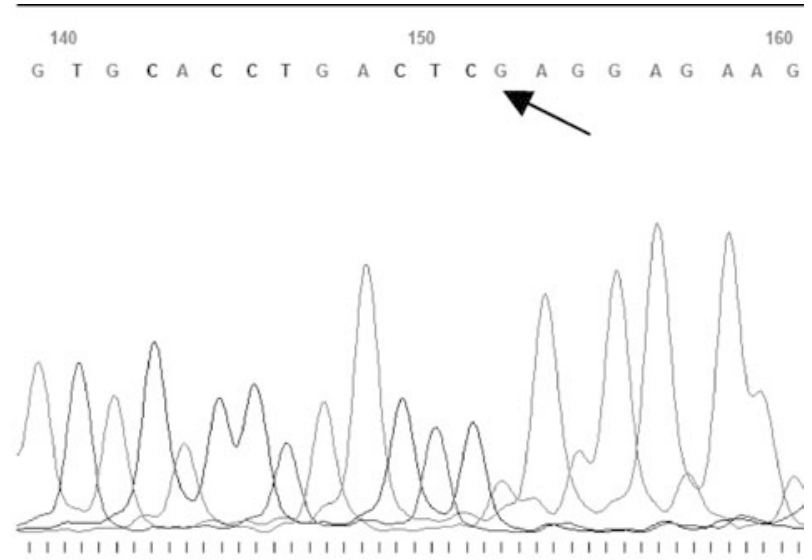

c.17_18delCT
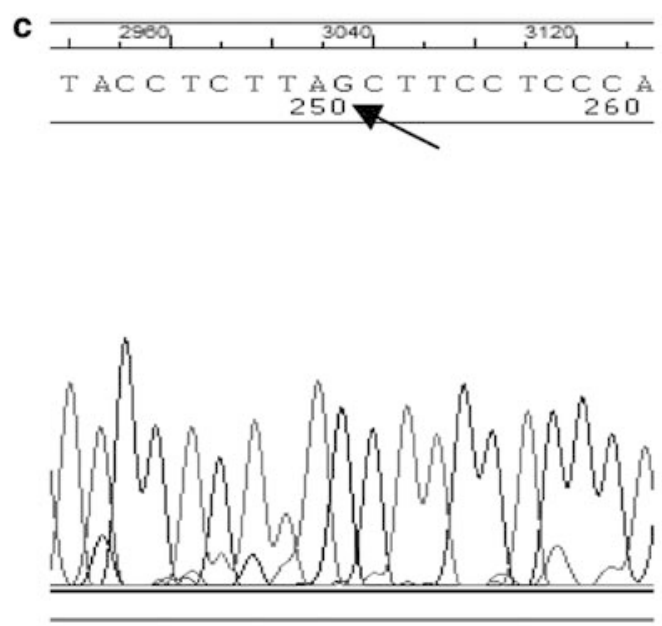

IVSII-14T>G

Fig. 2 Electropherograms showing the c. $93 \mathrm{G}>$ C, c.17_18delCT, and IVSII-14T $>\mathrm{G}$ mutations. Sequencing reactions were carried out on a Beckman \& Coulter CEQ 8000 genetic analysis system (Beckman \& Coulter Inc., Fullerton, CA, USA) and the ABI Prism 3100 genetic analyzer (Applied Biosystems, Foster city, CA, USA) as per the manufacturers' instructions. Panel a c.93G >C mutation; Panel b c.17_18delCT mutation; and Panel c IVSII-14T $>$ G mutation

the second frequent mutation detected (six cases, Table 2). Two cases each of c.366_494del, c.92G $>$ C, c.79G $>\mathrm{A}$ and c.27_28insT and one case each of c. $20 \mathrm{~A}>\mathrm{T}$ and the IVSII-14T $>\mathrm{G}$ were also detected (Table 2). Three cases of compound heterozygotes were identified; two harbored the c.79G $>A$ and IVS1 $+5 \mathrm{G}>\mathrm{T}$ mutations, whereas the third harbored the c.366_494del and IVS1 $+5 \mathrm{G}>\mathrm{T}$ mutations (Table 2). A All prenatal cases received were promptly screened and genetic counseling was provided.

During the evaluation of one sample by the RDB technique, the PCR product did not hybridize either to the wild type or to the mutant oligonucleotides for the IVS1 $+1 G>T$ (first base of the first intron) and the
IVS1 $+5 \mathrm{G}>\mathrm{T}$ (fifth base of the first intron) mutations. The observation was confirmed by repeated testing. Since the clinical phenotype of the patient gave a strong indication for $\beta$-thalassemia and the electrophoretic pattern of hemoglobin (variant analysis) from the parents confirmed the carrier status, DNA sequencing was carried out to identify the mutation in the patient. The electropherogram confirmed the presence of the $\mathrm{c} .92 \mathrm{G}>\mathrm{C}$ mutation (Fig. 2). Two more cases were screened with identical results. Sequencing reactions performed on parents of all three patients confirmed their heterozygous status (data not shown). A possible explanation for the absence of hybridization to the mutant as well as wild type oligonucleotides representing IVS $1+1 \mathrm{G}>\mathrm{T}$ and $\mathrm{IVS} 1+5 \mathrm{G}>\mathrm{T}$ mutations in the RDB is that the mutation c. $92 \mathrm{G}>\mathrm{C}$ is included within these oligonucleotides. Therefore, when RDB analysis reveals no binding to the wild type and mutated oligonucleotides at the IVS $1+1 \mathrm{G}>\mathrm{T}$ and the IVS1 $+5 \mathrm{G}>\mathrm{T}$ positions, it can be used as an indicator for the c. $92 \mathrm{G}>\mathrm{C}$ mutation.

The c. $92 \mathrm{G}>\mathrm{C}$ is a rare mutation in India. Very few cases with this mutation have been reported from North 
and East India (Verma et al. 1997; Kukreti et al. 2002; Gupta et al. 2003). To our knowledge, this is the first report of the mutation from South India. Two more rare mutations were identified in this study viz. the c.17_18delCT and IVSII-14T $>\mathrm{G}$ mutations (Fig. 2). Genomic DNAs isolated from parents of both patients were also subjected to DNA sequencing, and the results revealed a heterozygous state for each of the two mutations (data not shown). Although rare, the c.17_18delCT was reported earlier from the Indian population in immigrants from Pakistan (Verma et al. 1997) and also in the North Indian city of Lucknow (Agarwal et al. 2000). However, there is no report to date of the existence of the IVSII-14T $>$ G mutation in the Indian population. This mutation was earlier detected in Asian immigrants in the UK by Varawalla and colleagues (Varawalla et al. 1991a). The mutation resides $14 \mathrm{bp}$ upstream of the third exon and creates an alternative $3^{\prime}$ splice site that may be preferentially utilized, thereby leading to abnormal splicing of $\beta$-globin mRNA, resulting in the formation of a nonfunctional $\beta$-globin gene product.

Two of the three families harboring the c. $92 \mathrm{G}>\mathrm{C}$ mutation and the family harboring the c.17_18delCT mutation were from the South Indian state of Karnataka. The third family harboring the c.92G $>\mathrm{C}$ and the family harboring the IVSII-14T $>$ G mutation were from the South Indian state of Andhra Pradesh.

\section{Discussion}

$\beta$-thalassemia is a common hemoglobinopathy in India as per WHO records. Despite efforts to develop gene therapy or bone marrow transplantation, prenatal diagnosis followed by termination of the affected fetus remains the best form of management. Frequency of common mutations resulting in $\beta$-thalassemia in India have been carried out previously (Verma et al. (1997); Dastidar et al. (1994); Garewal et al. (1994)). However, representation of cases from South India was much less. $\beta$-thalassemia mutations from the Indian state of Tamilnadu have been reported earlier (Varawalla et al. (1991a), but none from the other South Indian states of AP, Karnataka, or Kerala. Our study includes for the first time a significant number of cases from AP, which, based on our results, appears to be a $\beta$-thalassemia hot-spot region. The study has revealed the complete absence of IVS1 $+1 \mathrm{G}>\mathrm{T}$ mutation and c.366_494del deletion mutation, which are comparatively common in the $\beta$-thalassemia cases from North India [Verma et al. (1997); Varawalla et al. (1991a,b)]. The present study has revealed a quick diagnostic tool for detection of the c. $92 \mathrm{G}>\mathrm{C}$ mutations based on the results obtained in the RDB screening. Moreover, we have also revealed the existence of two rare mutations, one of which is the first report from India.

Barring three cases, all samples analyzed in the study harbored homozygous mutations. Given the wide variety of $\beta$-thalassemia mutations reported worldwide, one would expect a higher proportion of compound heterozygous mutation. This is probably a result of a combination of two factors: firstly, a tendency among South Indian rural families to marry within one's family (mainly first cousin or uncle/niece marriages) and secondly, the high frequency of occurrence of a few mutations in the population (the IVS1 $+5 \mathrm{G}>\mathrm{T}$ and the c. $47 \mathrm{G}>\mathrm{A}$ mutations account for more than $80 \%$ of all cases analyzed in this study). Consanguineous marriages appear to be an important factor in the high frequency of occurrence of this disease and are more common in the Muslim community than the Hindu community.

The present study therefore, provides for the first time, data on $\beta$-thalassemia mutation frequencies in the South Indian State of AP. Therefore, carrier status detection and genetic counseling is highly significant. This study has been successfully extended to provide genetic counseling to affected families in terms of carrier detection, antinatal screening, and prenatal diagnosis. Thus, prenatal diagnosis in all high-risk families should be essential and should go a long way in reducing the burden of $\beta$-thalassemia in this region. With no effective prevention available for $\beta$-thalassemia, carrier detection and prenatal diagnosis are the most feasible modes of prophylaxis available. Our efforts are an important step to complete the catalogue of mutations from the South Indian population.

Acknowledgements We thank all physicians and hospitals of AP and other states for sending to us patients or blood samples for this study. We also thank the families of the patients for their cooperation. This work was supported by a Core Grant from the Department of Biotechnology, Government of India, to the CDFD, Hyderabad.

\section{References}

Agarwal S, Hattori Y, Agarwal SS (2000) Rare beta-thalassemia mutations in Asian Indians. Am J Hematol 65:322-323

Agarwal S, Gupta A, Gupta UR, Sarwai S, Phadke S, Agarwal SS (2003) Prenatal diagnosis in $\beta$-thalassemia: an Indian experience. Fetal Diagn Ther 18:328-332

Cai SP, Wall J, Kan YW, Chehab FF (1994) Reverse dot blot probes for the screening of $\beta$-thalassemia mutations in Asians and American blacks. Hum Mutat 3:59-63

Dastidar DG, Dutta RN, Gupta P, Old JM (1994) Detection of $\beta$-thalassemia in eastern Indian population by polymerase chain reaction. Ind $\mathbf{J}$ Med Res 100:111-114

Garewal G, Fearon CW, Warren TC, Marwah N, Marwah RK, Mahadik C, Kazazian JJ Jr (1994) The molecular basis of $\beta$-thalassemia in Punjab and Maharastrian Indians indicates a multilocus etiology involving triplicated $\beta$-globin loci. $\mathrm{Br}$ J Haematol 86:372-376

Gupta A, Hattori Y, Gupta UR, Sarwai S, Nigam N, Singhal P, Agarwal S (2003) Molecular genetic testing of beta-thalassemia patients of Indian origin and a novel 8-bp deletion mutation at codons 36/37/38/39. Genet Test Summer 7:163-168

Gurgey A, Becsac S, Mesci L, Cakar N, Karakas U, Kutlar A, Altay C (1993) Prenatal diagnosis of sickle cell anemia using PCR and restriction enzyme Dde I. Turk J Pediatr 35:159-162

Kukreti R, Dash D, E VK, Chakravarty S, Das SK, De M, Talukder $\mathrm{G}$ (2002) Spectrum of $\beta$-thalassemia mutations and their association with allelic sequence polymorphisms at the $\beta$-globin gene cluster in an Eastern Indian population. J Hematol 70:269-277 
Maggio A, Giambona A, Cai SP, Wall J, Kan YW, Chehab FF (1993) Rapid and simultaneous typing of hemoglobin S, hemoglobin $\mathrm{C}$, and seven Mediterranean $\beta$-thalassemia mutations by covalent reverse dot-blot analysis: application to prenatal diagnosis in Sicily. Blood 81:239-242

Miller SA, Dykes DD, Polesky HF (1988) A simple salting out procedure for extracting DNA from human nucleated cells. Nucleic Acids Res 16:1215

Newton CR, Graham A, Heptinstall LE, Powell SJ, Summers C, Kalshekar N, Smith JC, Markham AF (1989) The amplification refractory mutation system (ARMS). Nucleic Acids Res 17:2503-2516

Old JM (1986) In: Davies KE (ed) Genetic analysis of the human disease: a practical approach. IRL, Oxford, pp 1-17

Old JM, Varawalla NY, Weatherall DJ (1990) Rapid detection and prenatal diagnosis of $\beta$-thalassaemia: studies in Indian and Cypriot populations in the UK. Lancet 33:834-837
Varawalla NY, Old JM, Sarkar R, Venkatesan R, Weatherall DJ (1991a) The spectrum of $\beta$-thalassemia mutations on the Indian subcontinent: the basis for prenatal diagnosis. $\mathrm{Br} \mathbf{J}$ Haematol $78: 242-247$

Varawalla NY, Old JM, Weatherall DJ (1991b) Rare beta-thalassaemia mutations in Asian Indians. Br J Haematol 79:640-644

Verma IC (1994) The challenge of genetic disorders in India. In: Molecular genetics and gene therapy-the new frontier. Scientific Communications, Amsterdam, pp 11-20

Verma IC, Saxena R, Thomas E, Jain PK (1997) Regional distribution of $\beta$-thalassemia mutations in India. Hum Genet 100:109 113 